\title{
Interactive comment on "Time dependent, non-monotonic response of warm convective cloud fields to changes in aerosol loading" by Guy Dagan et al.
}

\section{Anonymous Referee \#2}

Received and published: 22 September 2016

Interactive comment on "Time dependent, non-monotonic response of warm convective cloud fields to changes in aerosol loading" by Guy Dagan et al. (MS No.: acp2016-736)

Comments to the Author:

The manuscript investigated cloud-aerosol interaction in warm cloud environment using a Large Eddy Simulations (LES) with bin microphysics. The paper is generally well written, contains some potentially interesting model results, but does not go into sufficient detail in any one of the cases and there is no comparison with observations which is necessary for a reality check. The article can be considered for publication after major revision. 
Some specific comments and suggestions follow:

1. The algorithm of cloud-aerosol interaction in the model is not clear. Suggest to elaborate the section 2 (methodology) in details. How the aerosol initiations are taking place? What is the composition of aerosols they have considered in their model? 2. Does the model take nucleation scavenging? Need to be cleared. 3. How does different size distribution of aerosols (CCN) affect the DSD? What is the effect of large $\mathrm{CCN}$ on the processes of droplet nucleation? 4. Authors have discussed on the role of aerosol on collision-coalescence, delayed surface rain in their introduction (line 5356) and also about cloud invigoration mechanism in line 80-83. In this context authors should put the references (Hazra et al. 2013a, Journal of Atmospheric Science; Hazra et al. 2013b, Journal of Geophysical Research-Atmosphere) studied cloud-aerosol interactions using 2 moment bulk microphysical scheme (Cheng et al. 2007, QJRMS) in meso-scale model. In this regard, I suggest refer/include all those papers in the manuscript. 5. Line 87-91: How aerosol impact on cloud fraction (CF), discussion not clear. Line: 169-172: Authors have mentioned the aerosols number concentration. Is it total concentration of all bins? Or which bin size of aerosols number concentrations they are increasing. This should be cleared to the readers. 6. Line 177-179: Authors mentioned "the eight simulated cloud fields are examined first". Are the eight simulated cloud fields are in similar or different. Need to be explained. 7. In Figure 1 and Figure 6: Total liquid water mass, LWP, CF and rain rate show a "tipping" point. It will be worthy if authors discuss on the "tipping point" as revealed in Figure 1 and 6 . Another important point authors should explain why the "tipping point" for total water mass, LWP are different from the CF and rain rate. 8. Can authors consider another aerosol concentration at lower rage? Authors have showed the response of vertical wind (updraft) to varying CCN concentrations (Figure 3A). 9. It shows updraft is monotonically increasing with aerosol concentrations. Is it correct? Need to be explained. 10. Another doubt: Figure 1B and Figure 4: Figure 1B shows clear tipping point of LWP, first it increases then it decreases, whereas when I am looking into the Figure 4, LWC increasing with aerosol number concentrations. Authors should make it unambiguous. 11. Time dependent

Interactive comment
Printer-friendly version

Discussion paper 
part (Figure 6, line 338-349) is not much convincing. Need to be explained in details. 12. It will be worthy if authors provide cloud drop number concentration and cloud drop size with increasing aerosol concentration. 13. Can authors put some hints of cloud-aerosol interactions in the mixed-phase clouds in their "Conclusion" section? 14. Comments Line 35-36: It is not only depends on CCN concentrations, also depends on availability of water vapor. 15 . The authors probably should proof read the manuscript carefully to correct some typos.

References: Cheng CT, Wang WC, Chen JP. 2007. A modeling study of aerosol impacts on cloud microphysics and radiative properties. Quart. J. Roy. Meteor. Soc., 133: 283-297. Hazra A, Goswami BN, Chen JP. 2013a. Role of Interactions between Aerosol Radiative Effect, Dynamics and Cloud Microphysics on Transitions of Monsoon Intraseasonal Oscillations. Journal of Atmospheric Sciences, 70: 2073-2087, DOI: 10.1175/JAS-D-12-0179.1, 2073-2087. Hazra A., Mukhopadhyay P., Taraphdar S., Chen J-P., Cotton W.R. 2013b. Impact of aerosols on tropical cyclones: An investigation using convection-permitting model simulation. Journal of Geophysical Research, 118, 7157-7168, DOI:10.1002/jgrd.50546.

Interactive comment on Atmos. Chem. Phys. Discuss., doi:10.5194/acp-2016-736, 2016. 